\title{
PRÁTICA PEDAGÓGICA EM CLASSES MULTISSERIADAS
}

\author{
Elane Rodrigues de Oliveiral \\ Maria Iolanda Monteiro²
}

\begin{abstract}
RESUMO
Este texto é resultado da pesquisa de mestrado intitulada "Educação no meio rural: a prática das professoras alfabetizadoras nas classes multisseriadas no município de Indaiabira-MG", que objetivou analisar as práticas pedagógicas existentes nas escolas multisseriadas no município. Para melhor compreensão do objeto em estudo, nos aproximamos de uma visão histórico crítica, o Materialismo HistóricoDialético. Utilizou-se uma abordagem metodológica qualitativa, teórica e de campo. Os resultados permitiram identificar inúmeras dificuldades que envolvem as escolas multisseriadas. Considera-se que a educação escolar, ofertada no meio rural em salas multisseriadas nas escolas observadas, apresenta problemas pedagógicos e de infraestrutura, aspectos que de acordo com as professoras entrevistadas dificultam o próprio trabalho, bem como o desenvolvimento dos alunos. Para tanto, requerem um repensar as questões políticas econômicas, sociais e pedagógicas.
\end{abstract}

Palavras-chave: Escolas multisseriadas. Educação no campo. Prática pedagógica.

\section{PEDAGOGICAL PRACTICE IN MULTIGRADE CLASSES}

\begin{abstract}
This text is the result of master's research entitled "Education in rural areas: the practice of literacy teachers in multigrade classes in the municipality of IndaiabiraMG", which aimed to analyze the existing pedagogical practices in multigrade schools in the municipality. To better understand the object under study, we approached a critical historical view, the Historical-Dialectical Materialism. A qualitative, theoretical and field methodological approach was used. The results allowed us to identify numerous difficulties involving multigrade schools. It is considered that the school education offered in rural areas in multigrade classrooms in the observed schools, presents pedagogical and infrastructure problems, aspects that, according to the interviewed teachers, hinder their own work, as well as the development of students. Therefore, they require a rethinking of political, economic, social and pedagogical issues.
\end{abstract}

Keywords: Multi-serial schools. Education in the countryside. Pedagogicalpractice.

\section{PRÁCTICA PEDAGÓGICA EN LAS CLASES MULTIGRADO}

\footnotetext{
1 Doutoranda em Educação. Universidade Federal de São Carlos, São Carlos, São Paulo, Brasil. Orcid iD: https://orcid.org/0000-0002-5747-7219. E-mail: elane.ufscar@yahoo.com.br

2 Professora do Programa de Pós-Graduação em Educação e do curso de Licenciatura em Pedagogia. Universidade Federal de São Carlos, São Paulo. Orcid iD: https://orcid.org/00000002-4534-1437. E-mail: mimonteiro@ufscar.br
} 


\section{RESUMEN}

Este texto es el resultado de una investigación de maestría titulada "La Educación en el medio rural: la práctica de los alfabetizadores en clases multigrado en el municipio de Indaiabira-MG", que tuvo como objetivo analizar las prácticas pedagógicas existentes en las escuelas multigrado del municipio. Para una mejor comprensión del objeto en estudio, nos acercamos a una visión histórica crítica, el Materialismo Histórico-Dialéctico. Utilizamos un enfoque cualitativo, teórico y de campo. Los resultados nos permitieron identificar numerosas dificultades que afectam a las escuelas multigrado. Se considera que la educación escolar que se ofrece en las zonas rurales en aulas multigrado de las escuelas observadas, presenta problemas pedagógicos y de infraestructura, aspectos que, según los docentes entrevistados, dificultan su propio trabajo, así como el desarrollo de los alumnos. Por lo tanto, requieren un replanteamiento de las cuestiones políticas, económicas, sociales y pedagógicas.

Palabras clave: Escuelas multigrado. La educaciónenel campo. Práctica pedagógica.

\section{INTRODUÇÃO}

Este artigo propõe uma reflexão acerca das escolas multisseriadas, a partir do recorte da pesquisa qualitativa realizada no município de Indaiabira, região norte de Minas Gerais, entre os anos de 2019-2020. É resultado da pesquisa de mestrado em educação na Universidade Federal de São Carlos- UFSCar, cujo tema é: Educação no meio rural: a prática das professoras alfabetizadoras nas classes multisseriadas no município de Indaiabira-MG. Os dados coletados e estudos realizados se deram visando conhecer as condições postas no funcionamento e na permanência destas escolas. Bem como refletir as perspectivas, avanços e desafios evidenciados por sujeitos que lidam com esta modalidade de ensino, nesse caso, as professoras alfabetizadoras, as quais foram fundamentais no processo de desenvolvimento da pesquisa.

Desta maneira, o presente artigo tem como objetivo analisar as práticas pedagógicas das professoras alfabetizadoras que atuam nas salas multisseriadas. O nosso olhar se deu à luz do referencial teórico do materialismo histórico dialético de inspiração marxista, nos fundamentos teóricos das investigações desenvolvidas por Karl Marx nos aspectos 
filosóficos, históricos, econômicos e político-sociais. A metodologia foi desenvolvida com base em uma pesquisa qualitativa com ênfase em um estudo de caso (LÜDKE; ANDRÉ, 1986), em quatro escolas públicas municipais, localizadas na zona rural do município de Indaiabira/MG. Para tanto, realizamos entrevistas com quatro professoras de classes multisseriadas, as quais também responderam a um questionário, bem como coletamos e selecionamos dados, tanto bibliográficos, quanto observacionais no campo pertinentes à pesquisa.

Há de se considerar que as escolas multisseriadas se caracterizam como uma realidade em todo o mundo, principalmente nas regiões Norte e Nordeste brasileiro, além de ser regulada na norma jurídica junto a outras possibilidades de agrupamento de ensino, como sinalizado no artigo $23 \mathrm{da}$ Lei de Diretrizes e Bases da Educação Nacional - LDBEN/96 (BRASIL).

De acordo com Ferri (1994)

As escolas com classes multisseriadas têm uma longa história. Foram - e continuam sendo - os primeiros tipos de escolaridade possíveis para as zonas rural e urbano periféricas (embora sejam maioria nas zonas rurais). Sua característica básica, a de reunir em torno de um professor vários alunos de séries diferentes, data de décadas atrás e perpetua-se até hoje, embora na história da educação brasileira existam apenas vagas notícias sobre a educação rural e a educação da população em geral, excetuando-se o caso daquela dirigida aos filhos das elites e a "catequese jesuítica". (FERRI, 1994, p.28)

Sendo a multissérie uma modalidade de ensino presente na atualidade, com predomínio de um único professor atender diversas séries no mesmo tempo e espaço, as salas multisseriadas vêm sendo rotuladas como atrasadas e de má qualidade, ao mesmo tempo, ainda que tímida, tem sido objeto de estudo de pesquisas que contribuem para reverter essa situação de abandono vivenciada pelos sujeitos do campo. Assim sendo, Parente (2014) afirma que

A nomenclatura multisseriação está carregada de sentido negativo [...] que tem limitado a prática pedagógica [...]. Mais 
do que isso, é uma adjetivação que rotula, classifica e associa a multisseriação a um tipo de escola de baixa qualidade, fraca, difícil, trabalhosa, errada, isolada. Mas as escolas multisseriadas têm vida. Não são apenas resultados de políticas ou de ausência delas. Elas se criam e recriam em meio às inoperâncias burocráticas, às legislações, aos programas que começam e terminam, às lutas pelo direito à educação de qualidade. E é nesse contexto que surgem inovações e transgressões no cotidiano escolar. Com a escola multisseriada, esse processo não é diferente. Apesar dos rótulos, muitas têm buscado exercer sua função sociopolítica e pedagógica; apesar do fardo, têm superado as imposições do termo, buscando romper com os encaixes e padronizações desnecessárias. (PARENTE 2014, p. 60)

Diante disso, apesar de todas as mazelas advindas desde a década de 1980, estas escolas são geralmente a única alternativa dos filhos de trabalhadores terem acesso à educação escolar, assim, as escolas multisseriadas vêm resistindo e adentraram o século XXI. Neste contexto, Arroyo (2010, p.9) salienta a importância de romper com o imaginário negativo das escolas multisseriadas, "obrigam-nos a redefinir olhares e superar visões inferiorizantes, negativas, com que, em nosso viciado e preconceituoso olhar, classificamos os povos do campo [...]". O autor afirma também que essa visão negativa ainda tenha uma intencionalidade política perversa, de modo a reduzir o campo, tornando-o invisível e inexistente. Assim, acredita que "enquanto esses imaginários e paradigmas hierarquizantes, inferiorizantes, segregadores persistirem as pesquisas e análises nascerão viciadas, preconceituosas". (ARROYO, 2010, p.11)

Nesta direção, o presente artigo procurou apontar de que maneira as práticas pedagógicas das professoras alfabetizadoras nas escolas multisseriadas no município de Indaiabira vêm se materializando, aspectos abstraídos de observações da pesquisa sobre as escolas multisseriadas, realizadas pelas autoras. Diante disso, o trabalho apresentará o contexto geral vivenciado pelas escolas multisseriadas do referido município, aspectos que vão desde o lócus da pesquisa, as escolas multisseriadas existentes no município e os sujeitos que compõem a organização escolar, por último, apresentamos a prática pedagógica das professoras alfabetizadoras das 
escolas analisadas. A partir de contatos estabelecidos com as professoras que atuam em salas multisseriadas com alunos dos anos iniciais do ensino fundamental, secretaria municipal de educação, bem como de observações e diálogos constituídos junto à comunidade.

\section{O lócus da pesquisa}

O presente trabalho consiste em refletir sobre a prática pedagógica das professoras alfabetizadoras das escolas multisseriadas no município de Indaiabira. A pesquisa de campo foi realizada no período de 2019 a 2020 , em quatro "prédios" - escolas rurais do município, visando compreender onde e como essas escolas estão localizadas, aspectos que perpassam entre as questões estruturais e pedagógicas. Para tanto, a pesquisa contou com a participação de 4 professoras que trabalham com os anos iniciais do ensino fundamental. Na pesquisa de campo foi utilizado, como procedimento metodológico para a coleta de dados, entrevistas e questionários, na tentativa de obter maiores esclarecimentos quanto à prática dessas professoras.

Minas Gerais, assim como demais estados brasileiros, constituiu um processo de implementação e oferta de educação escolar no campo de forma isolada, situação na qual muitas das escolas multisseriadas presentes, atualmente, foram constituídas. Com o passar dos anos as discussões, articulações de construir propostas de acordo com as especificidades do espaço rural, visando a melhoria do ensino, multiplicaram-se pelo país, com destaque a partir da década de 1980, a luta dos movimentos sociais por uma educação do campo adequado às suas realidades e demandas, assim como as políticas de nucleações das escolas multisseriadas. Mesmo com o fechamento e nucleações de escolas, muitas escolas multisseriadas mineiras resistiram, permanecendo presentes em diversas comunidades, como é o caso de Indaiabira, localizada na região norte do estado de Minas. Escolas estas responsáveis pelo atendimento escolar dos anos iniciais do ensino fundamental e a única opção de localização com maior proximidade da residência dos alunos. 
O município de Indaiabira localiza-se na mesorregião norte do estado de Minas Gerais, na microrregião de Salinas e compõe, junto com outros municípios, o território Alto Rio Pardo 3 . Um município de pequeno porte, com as principais atividades econômicas relacionadas ao campo, a opção por esse município se deu por haver inúmeras inquietudes relacionadas à infraestrutura e organização das escolas localizadas nas áreas rurais. A cidade de Indaiabira está situada a $525,90 \mathrm{~km}$ de distância da capital Belo Horizonte em linha reta e $728 \mathrm{~km}$ de condução.

De acordo com David (2000) nas incursões para as Minas Gerais, motivadas pela exploração de riquezas minerais pelas "crises" e, mais tarde, pelo comércio através dos tropeiros, a região do município de Indaiabira, qual oásis no meio do deserto sertanejo, foi atração e refúgio para centenas de pessoas vindas das regiões assoladas. Alguns se fixaram e passaram a integrar o contingente populacional.

O município de Indaiabira é uma região semiárida de bioma cerrado e mata atlântica, tendo como traço principal as frequentes secas, ou seja, ausência e escassez de chuvas. Do ponto de vista populacional, de acordo o Censo (BRASIL, 2017), a região apresenta 7.330 habitantes, com uma população estimada para o ano de 2019 de 7.351 habitantes, dos quais 2.742 habitantes vivem na área urbana e 4.588 habitantes na área rural do município.

\section{As escolas multisseriadas no município de Indaiabira}

Na oportunidade em que se realizou a coleta de dados da presente pesquisa (2021), 04 escolas municipais ofertavam os anos iniciais do ensino fundamental multisseriado, havendo casos de duas dessas escolas atenderem, além do ensino fundamental, o pré-escolar de 04 e 05 anos. A média do número máximo de alunos nessas escolas são de 50 alunos e o

\footnotetext{
${ }^{3}$ O Território Alto Rio Pardo constituiu-se por um conjunto de municípios unidos pelas mesmas características econômicas e ambientais, com identidade e coesão social, cultural e geográfica, o Território do Alto Rio Pardo que já era território rural, sendo esta, política de desenvolvimento territorial implantada pelo governo Lula, em 2004, ganha status de território da cidadania em 2010 (BRASIL, 2015).
} 
mínimo de 10 alunos, sendo esses das referidas comunidades e de outras ao entorno. As escolas estão localizadas entre 13 a 40 km de distância da sede Indaiabira.

As escolas visitadas revelaram condições físicas precárias, com paredes que parecem não terem recebido há muito tempo uma "mão de tinta". Porém, ao avistar o seu interior em meio a paredes, muitas delas descascadas e piso desgastado, foi possível perceber o cuidado que aqueles sujeitos (professoras) têm com o seu espaço de trabalho e construção do conhecimento. Enriquecidas e ornamentadas pelas mãos das professoras e dos alunos, com elaborações que expressam seus saberes e fazeres, a fim de possibilitar maior desenvolvimento e acolhimento aos alunos.

Todas as 04 escolas visitadas estão localizadas na área rural do município. Cabe ressaltar a existência de uma escola, a qual funciona em uma casa alugada pela prefeitura municipal, adaptada para o funcionamento de salas de aula, também, uma das escolas visitadas é uma escola que até o ano de 2018 pertencia ao Estado de Minas Gerais, sendo então municipalizada. Desta maneira, as escolas, na sua maioria, possuem espaços improvisados e adaptados, praticamente sem estrutura de espaços, de equipamentos e recursos pedagógicos. Mesmo que muitas delas improvisadas, as escolas possuem salas, secretaria, cozinha, banheiros, ainda que bastante precários. Possuem energia elétrica, porém, não há rede de esgoto, além disso, pode- se considerar a inexistência da coleta de lixo nessas escolas.

Quanto à água utilizada nas escolas, essas não possuem água tratada, existindo casos em que o uso da água é feito através de captação do rio próximo da escola, nos períodos em que há água no rio, caso contrário, existe na escola uma caixa do Programa Água na Escola, realizado pelo Governo Federal na gestão de Luiz Inácio Lula da Silva, no período de 2002-2010, a qual tem sido abastecida por caminhão pipa encaminhado pela prefeitura municipal, as demais escolas são munidas de poço artesiano e/ou água encanada. Nota-se, nas escolas, a inexistência de 
outros espaços pedagógicos de suma importância, como: biblioteca; pátio; quadra esportiva; salas para reuniões e internet. Apenas uma escola possui uma sala de leitura em boas condições.

Ressaltamos, entretanto, que os quatro prédios escolares municipais, localizadas na área rural de Indaiabira, são prédios que necessitam de diversos reparos estruturais.

Essas análises permitiram visualizar as escolas municipais rurais multisseriadas do município de Indaiabira no ano de 2019, atrelada a essa situação, pode-se acrescentar o limitado recurso que é destinado a elas. Deparamo-nos com uma diversidade estrutural e pedagógica, o que evidenciou a necessidade de melhores condições básicas para as escolas rurais multisseriadas do município, principalmente das comunidades mais distantes da sede, pois, de acordo com os relatos, essas escolas costumam ficar com aquilo que resta das escolas localizadas em espaços com maior visibilidade aos olhos da sociedade, usando como exemplo as escolas localizadas na cidade, bem como as nucleadas no município. Mais uma vez chamamos a atenção do poder público para a elaboração de políticas benéficas ao meio rural, sobretudo à educação escolar.

\section{Os sujeitos da pesquisa}

Segundo o Projeto Pedagógico Político - PPP (BRASIL, 2019), as escolas municipais multisseriadas do campo atendem alunos com a faixa etária de 4 a 11 anos de idade, tendo eles um nível socioeconômico de classe baixa a média, alunos provenientes de famílias em condições socioeconômicas diversificadas, moradores de comunidades da zona rural deste município.

Em relação às condições socioeconômicas e culturais, podemos afirmar que a maioria das famílias é de baixa renda, sobrevivendo de serviços informais, os quais não geram uma renda fixa ou a garantia dos direitos trabalhistas, como carteira de trabalho assinada. Desempenhando, assim, atividades de pequenos agricultores. Ainda, segundo o PPP, outro dado que demonstra a renda destas comunidades é o número considerável de famílias atendidas por programas sociais, relatados na ficha de matrícula, 
como: Bolsa Família. A vida social e de lazer das famílias restringe à frequência à igreja e visitas familiares.

De acordo com o PPP, os alunos atendidos nas escolas, oriundos de outras comunidades, dependem do transporte escolar, o qual é oferecido pelo Governo Federal em contrapartida com o Governo Municipal. A maioria dos alunos não têm apoio da família nas tarefas escolares ou outros ambientes de aprendizagem que não seja a escola.

Quanto às professoras que participaram da pesquisa, três delas são mães. Todas as docentes pesquisadas disseram conhecer a comunidade onde trabalhavam e duas delas disseram serem líderes na igreja local. As professoras que não residem nas comunidades chegam até as mesmas via conduções próprias (carro, moto), segundo relatos, aqueles professores que moram a mais de $12 \mathrm{~km}$ de distância das escolas recebem uma ajuda de custo para ajudar no transporte. Duas professoras moram na área rural, uma na cidade e uma outra em um distrito no referido município.

As quatro professoras são formadas em Pedagogia à Distância, no período em que foi feita a pesquisa de campo (2019), duas professoras eram concursadas, as outras duas eram contratadas, com ressalva que uma das professoras concursadas possuía concurso para servente escolar e não para atuar em sala de aula. Apesar de todas as professoras possuírem formação superior, algumas delas relataram ter começado a docência sem formação na área ou mesmo sem ter concluído o curso de formação superior.

Nas falas das professoras P2 e P34, os primeiros anos de carreira foram os mais difíceis, marcados por momentos de dúvidas, medo, angústias e ao mesmo tempo significativos, pois contribuíram para o amadurecimento profissional. As professoras nem sempre tiveram a opção de lecionar próximo de suas casas. Várias foram as dificuldades enfrentadas por essas professoras, o que acontece com praticamente todos os professores iniciantes, porém, nesse caso específico, devido ao fato de terem ingressado

\footnotetext{
${ }^{4}$ As denominações P1, P2, P3 e P4 que aparecem ao longo do texto, embora as professoras tenham autorizado participar da pesquisa, são denominações fictícias no intuito de preservar suas identidades.
} 
na docência sem preparo suficiente e com uma frágil base de conhecimento para o ensino, o choque, principalmente com as salas multisseriadas, é ainda maior. A P3 relata uma experiência vivenciada no início de carreira, de acordo com sua enunciação, nota-se a desvalorização do sujeito da área rural, por parte da gestão municipal, ou seja, por ser uma "escolinha na área rural" qualquer pessoa serve, independente se possui formação na área ou não, independente das condições, o que importa é dizer que possui a oferta de educação naquela comunidade.

Cabe ressaltar que, de acordo com o PPP (BRASIL, 2019), no período em que foi desenvolvida a pesquisa, cem por cento dos professores das escolas do município de Indaiabira possui formação em curso superior, com licenciatura. É visto que, no que diz respeito à formação superior dos professores da educação básica do município de Indaiabira, tem avançado neste aspecto. Por outro lado, em relação à formação de professores que atuam em classes multisseriadas, seja formação inicial ou continuada, Hage (2005, p. 44) nos apresenta um quadro preocupante, no qual afirma que "boa parte dos que ensinam no campo têm formação carente; e apenas $9 \%$ completaram o ensino superior". Nesse contexto, o autor enfatiza que essa situação advém do descaso das instâncias governamentais para com as escolas do campo, em particular, as multisseriadas, pois fica evidente que as mesmas são discriminadas em relação às escolas da cidade, que têm prioridade em relação ao acompanhamento pedagógico e formação docente (HAGE, 2005).

Ao perguntar às professoras se ouviram falar sobre as classes multisseriadas durante a formação inicial, a P1, P2 e P4 disseram ter ouvido falar de forma superficial, já a P3 disse não se lembrar de ter sido tratado esse assunto durante o curso de formação inicial. Quanto à formação continuada oferecida pela SME, ou mesmo pela escola, no ano em que foi desenvolvida a pesquisa (já no $2^{\circ}$ semestre de 2019) não havia tido formação para professores, também podemos notar que as mesmas não realizaram nenhuma formação continuada por conta própria, seguido do 
desconhecimento de programas e conceitos que envolvem a alfabetização/letramento e educação do/no campo.

Diante disso, pode-se inferir que a formação continuada no município de Indaiabira ainda é insuficiente. As professoras relatam buscar a forma mais eficaz, as quais acreditam contribuir no desenvolvimento dos alunos, no entanto, reconhecem que é insuficiente frente à organização multisseriada, requerendo formação específica (na forma e nas condições) para tal modalidade de ensino, principalmente no ato de planejar as aulas.

\section{Prática pedagógica em classes multisseriadas}

Em se tratando de processo educacional, o fazer pedagógico recebe destaque, pois é nele que se estabelece a relação do ensinar e aprender, desse modo, para Veiga (1989), a relação que se estabelece entre os fatores do processo educativo é estabelecida a partir da prática pedagógica, visando fins e objetivos educativos.

Nesse sentido, podemos afirmar que toda ação pedagógica requer reflexão sobre a construção do saber, possibilitando maior desenvolvimento. Sendo assim, a prática pedagógica deve compreender que a educação é um processo histórico e social, que se determina no cotidiano escolar pelo trabalho do professor e de toda a comunidade escolar, suas ações e interação entre sujeitos. Postas estas considerações, damos sequência apresentando os dados coletados por meio da entrevista realizada com as professoras das classes multisseriadas no município de Indaiabira. As percepções destas professoras nos propiciaram pistas importantes de como a prática pedagógica vem sendo desenvolvida em uma sala multisseriada, suas angústias e possibilidades de ensino.

A partir da visita na sala de aula e entrevista com as professoras, percebe-se que a didática delas se dá com aulas expositivas, escrita no quadro, xérox, trabalhos em duplas ou em grupos, leituras, atividades dos livros didáticos, avaliações variadas (provas, trabalhos, etc.). Cabe ressaltar que todas as professoras entrevistadas afirmaram fazer uso de livros didáticos seriados e que esses não eram específicos para as salas multisseriadas. As 
professoras disseram realizar o planejamento semanalmente, com atividades diferenciadas para cada série/ano. De acordo com as professoras, o plano de aula não é completamente vencido, segundo o planejado, tendo que ser estendido, existindo fatores, os quais veremos no decorrer do texto que, conforme as professoras, impedem as possibilidades de realização do almejado.

Sobre o planejamento das atividades pedagógicas, a fala da P2 é bastante contundente, a partir do seu relato, podemos exemplificar a forma como as demais professoras também se organizam na sala multisseriada

Eu faço plano semanal, seguindo o planejamento que a gente faz o plano de curso, e eu faço plano para as cinco turmas, no caso do primeiro e do terceiro que eles estão mais ou menos no mesmo nível, algumas atividades eu dou as mesmas algumas não [...] então mesmo assim é um plano para cada, então é um pro pré, um para primeiro, um para o terceiro, quarto e quinto eu trabalho a mesma coisa porque os níveis deles, estão nos mesmos níveis, então a gente sentou com a supervisora pedagógica e ela falou assim que a gente fizesse - que achasse o que fosse desenvolver a turma, ai nós decidimos planejar para quarto e quinto os mesmos conteúdo. (P2)

De acordo com o relato da professora, o planejamento das aulas é a partir daquilo que planejam no plano de curso, ou seja, orientado pela supervisão pedagógica da Secretaria Municipal de Educação. A fala da professora demonstra "autonomia" para desenvolver o planejamento na sala de aula, no entanto, segue orientações e os mesmos livros didáticos destinados às salas seriadas, urbanas ou rurais. É assim que começam as dificuldades, à transposição do modelo seriado às turmas multisseriadas, visto que os próprios livros didáticos utilizados nas escolas pesquisadas são seriados, como afirma a P4 "Tanto é que têm os livros, né, livros do primeiro e do segundo. Os livros didáticos vêm para os dois, então precisa fazer planos diferentes". Isto é, "forçando-os a trabalharem com este modelo, o 
que consequentemente contribui com a dificuldade em conduzir o processo de ensino e aprendizagem" (NUNES, 2018, p.204).

É possível notar, nos depoimentos das professoras, que o modo de organização predominante é o desenvolvimento de diferentes planos de aula para cada série, no entanto, sobretudo na sala da P2, existem casos de realizar um único plano para duas turmas (séries diferentes), devido ao fato de considerar os alunos em nível de conhecimento similares. Dessa maneira, a professora P2 busca várias formas de desenvolver o trabalho docente a partir da necessidade e nível de aprendizagem dos alunos.

Estudos realizados pelo autor Hage (2005) evidenciam que

Os professores enfrentam dificuldades em realizar 0 planejamento nas escolas multisseriadas, porque trabalham com muitas séries ao mesmo tempo e a faixa etária, o interesse e o nível de aprendizagem dos estudantes são muito variados. A alternativa mais utilizada para viabilizar o planejamento tem sido seguir as indicações do livro didático, sem atentar com clareza para as implicações curriculares resultantes dessa atitude, uma vez que esses materiais didáticos têm imposto a definição de um currículo deslocado da realidade e da cultura das populações do campo da região. (HAGE, 2005, p.52)

Os estudos apontados por Hage (2005) identificam ainda as angústias sentidas pelos professores ao organizarem o trabalho pedagógico, justamente porque assumem a visão da multissérie enquanto "junção de várias séries ao mesmo tempo e num mesmo espaço" (HAGE 2005, p.52), tendo que elaborar vários planos de ensino e estratégias de avaliação da aprendizagem, diferenciadas de acordo com as séries as quais trabalham. Com isso, os professores se sentem angustiados e ansiosos ao pretenderem realizar o seu trabalho da melhor maneira possível, ao mesmo tempo, necessitam de recursos (físicos, pedagógicos, formação etc.) e de apoio para organizar o tempo, espaço e conhecimento escolar. Não suprindo, na maioria das vezes, as suas necessidades e as necessidades dos alunos, o que faz com que o planejamento e a organização do trabalho pedagógico se apresentem como entraves, principalmente, nas classes multisseriadas. 
Conforme Nunes (2018), o planejamento com atividades específicas para cada ano e etapa de ensino tem sido a saída encontrada pelos professores, ao mesmo tempo, tem sido um desafio. A autora afirma, ainda, que essa estratégia didática é ineficiente, pois os professores não dão conta de atender aos trabalhos que estão sendo desenvolvidos pelos alunos individualmente e nem por ano, assim "acabam por priorizar as crianças menores, que ainda estão no processo de alfabetização, em detrimento dos outros maiores sem 0 devido acompanhamento e intervenção para a construção do conhecimento" (NUNES, 2018, p. 205). Neste contexto, a autora defende que,

Deve-se compreender que 0 trabalho com as escolas multisseriadas não pode ser via seriação (dividido pelos anos escolares) como fazem os professores na hora do planejamento, não cabe planejamento para cada ano de ensino, é um único planejamento para a turma, o que diferenciará são as intervenções que a professora fará para cada ano e nível de desenvolvimento do aluno, para que possa ocorrer a aprendizagem. (NUNES, 2018, p. 207)

Para isso, a autora complementa dizendo que "faz-se necessária uma organização da sala de aula, que requer trabalho com o grupo de alunos heterogêneos, por ser justamente o que é mais rico nesse tipo de organização, valorizando-se a troca de saberes entre os pares" (NUNES, 2018, p. 207). Cabe, então, destacar a importância de o professor compreender e dominar os conteúdos de forma pedagógica e didática, além de conhecer o nível de desenvolvimento dos alunos, com objetivo de desenvolver atividades que possibilitem o aprendizado, e assim

Permitir que o pensamento chegue à síntese das múltiplas determinações de uma totalidade concreta, pois, um bom planejamento e condução do processo educativo requerem uma ação pedagógica que se integre à realidade concreta, em busca da transformação da realidade social. (NUNES, 2018, p. 207)

Em outras palavras, requer condições de ensino e do desenvolvimento de atividades que contribuam na formação de sujeitos comprometidos com 
a transformação social. Nesse contexto, diante das dificuldades enfrentadas nas escolas multisseriadas, não podemos cair no discurso da culpabilidade, isto é, as condições de trabalho existentes, as questões da precariedade do ensino em sala de aula não são de responsabilidade das professoras, por isso a importância de se compreender o papel da educação no interior do sistema de produção capitalista, o que requer aprofundamento das teorias educacionais, subsidiando, assim, uma análise crítica teórico-metodológico, políticas e práticas educacionais voltadas para a formação humana, em particular, para a formação dos sujeitos do campo.

Perguntamos às professoras como administram o tempo de $4 \mathrm{~h} 20$ minutos, na sala de aula, para as diversas turmas/séries, por exemplo, se o mesmo é um fator que atrapalha o desenvolvimento das atividades. Diante dos depoimentos das professoras, é notável a insatisfação, elas acreditam que a organização multisseriada e o tempo são fatores que dificultam o trabalho docente, que a dinâmica de trabalho acaba fracionando o tempo, e, consequentemente, prejudica o desenvolvimento dos alunos, o que requer um reordenamento curricular junto à multissérie. Cabe destacar que a $\mathrm{Pl}$ considera $\mathrm{O}$ ensino em sala multisseriada como um mau atendimento aos alunos, a partir do diálogo com essa professora, entendemos que esse mau atendimento envolve questões práticas, pedagógicas e de infraestrutura, ou seja, um conjunto de elementos necessários para o ensino e aprendizagem. Já a P4 acredita que "não é qualquer professor que trabalha não, ainda mais com alfabetização e segundo ano", a professora acredita que a complexidade do trabalho é ainda maior no processo de alfabetização dos alunos.

A partir da manifestação da P2, essa acredita ser o modelo de organização multisseriada fator principal e responsável que desencadeia nas dificuldades apresentadas pelos alunos do $5^{\circ}$ ano e principalmente nos anos finais do ensino fundamental, levando em consideração que esses alunos, na maioria das vezes, estudam do pré-escolar ao $5^{\circ}$ ano em salas multisseriadas nas áreas rurais. Caso continuem os estudos, são obrigados a se deslocarem para os povoados e ou cidade, para as turmas seriadas. 
É importante ressaltar que, para além da organização em sala multisseriada citada pelas professoras ao longo das entrevistas, são notáveis outros fatores que julgamos dificultar o trabalho pedagógico, como a falta de infraestrutura, materiais didáticos-pedagógicos, baixa remuneração, apoio pedagógico insuficiente por parte de alguns responsáveis, dentre outros, visto que estas dificuldades não são exclusividade das classes multisseriadas.

Ao perguntar às professoras entrevistadas o que é ser docente em uma classe multisseriada, as respostas foram similares. Demonstraram-se sentirem desafiadas a todo o momento. Diante das falas destacadas, pode-se constatar que são unânimes as dificuldades apresentadas pelas professoras. Todas elas têm a clareza dos desafios encontrados ao trabalhar em uma classe multisseriada. Não podemos desconsiderar a opinião das professoras envolvidas com a multissérie, a qual considera

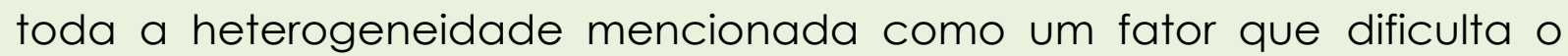
trabalho pedagógico.

Por outro lado, "se tem generalizado na sociedade que as "classes homogêneas' são o parâmetro de melhor aproveitamento escolar e, consequentemente, de educação de qualidade" (HAGE, 2005, p. 58). Contudo, as professoras enxergam, nas turmas heterogêneas, o maior desafio, junto a isso se dá a dificuldade em organizar o tempo didático para que o ensino aconteça. Frente a isso, estudos realizados por Hage (2005) demonstram que a heterogeneidade deve ser valorizada e incorporada nos processos e espaços de elaboração e implementação de políticas e propostas educacionais para cada região, sendo então melhor aproveitada.

Dessa maneira, faz-se necessário que os professores identifiquem elementos que precisam ser assimilados pelos indivíduos, esta identificação envolve distinguir o que é essencial do que é secundário, ou seja, a escola precisa se ocupar mais com os conteúdos científicos, sendo esta a função social da escola como afirmado por Saviani (2011). Nesse contexto requer repensar o currículo, metodologias e a 
organização do trabalho pedagógico nas escolas, de modo que contemple as necessidades dos sujeitos do campo. E, assim, fazer reconhecer a importância de uma educação de qualidade social para as classes multisseriadas, já que as mesmas têm sido, até o presente momento, a maneira utilizada para atender e manter as populações do campo em seu próprio espaço, sem que precise se deslocar para os centros urbanos. Hage (2005) conclui dizendo que

As escolas multisseriadas oportunizam às populações do campo terem acesso à escolarização no lugar em que vivem, em sua própria comunidade, fator que poderia contribuir significativamente para a permanência dos sujeitos no campo e para a afirmação de suas identidades culturais, não fossem todas as mazelas que envolvem a dinâmica educativa efetivada nessas escolas (HAGE, 2005, p.57)

Diante dos desafios apresentados pelas professoras ao trabalharem com classes multisseriadas, relembramos as dificuldades de infraestrutura e pedagógica que as escolas multisseriadas se encontram. Verificamos que as escolas são vistas como reivindicação social enquanto direito público. Estas escolas possuem um papel de pertencimento dos sujeitos que ali vivem, haja vista que há o interesse que os alunos estudem em escolas nas próprias comunidades. No entanto, apesar de existir a oferta da educação básica nas próprias comunidades, estas escolas não têm ofertado condições básicas para um melhor desenvolvimento do ensino escolar. Entendemos por condições básicas o abastecimento de água e esgoto sanitário; energia elétrica, bem como a existência de sanitários; salas, diretoria; secretaria; funcionários; biblioteca; materiais pedagógicos; quadra de esporte; refeitório; ônibus apropriados para o transporte de alunos; sobretudo, professores com formações que dialoguem com a realidade multisseriada, além de bem pagos, entre outros.

Embora ao longo da entrevista as professoras tenham apresentado dificuldades em relação às classes multisseriadas, conseguimos destacar 
nos seus depoimentos que elas carregam dentro de si algo que as motiva na profissão docente. Percebe-se, nas suas falas, a esperança de dias melhores. Contudo, nos leva a inferir a necessidade das professoras se apropriarem de conhecimentos teóricos mais críticos, despertando-nas o desejo de mudança, possibilitando uma relação entre teoria e prática, visando contribuir para o desenvolvimento dos alunos. Além disso, é necessário que a escola reconheça o seu papel social e proporcione meios para a oferta de uma educação que torne os sujeitos pessoas conhecedoras, críticas, e, acima de tudo, transformadores da sociedade desigual.

\section{CONSIDERAÇÕES FINAIS}

Em suma, ao final desta análise, conhecimentos e reflexões do contexto encontrado no município de Indaiabira-MG, o que se constata neste estudo são escolas em situações precárias, atendendo as prioridades da sociedade vigente, reafirmando o caráter elitista e excludente do modelo econômico, o acesso ao saber parcial das coisas, naturalização e domesticação para o capital. Compreendeu-se, a fim de possibilitar melhorias no acesso e oferta da educação escolar em salas multisseriadas, que se deve levar em consideração as especificidades dos sujeitos do campo, o acesso aos conhecimentos historicamente sistematizados, investimentos em formação de professores e melhores condições de trabalho e salário, acompanhamentos, condição primordial didático, pedagógico e estrutural.

Vimos que o planejamento e a organização do trabalho pedagógico são apresentados como entraves na organização escolar multisseriada. Sem orientações que atendam as especificidades dos sujeitos do campo das escolas multisseriadas e, como consequência, há uma adaptação do ensino seriado urbanocêntrico, sendo assim, não Ihes restam alternativas que não seja seguir os critérios já pré-definidos, propostas educacionais desconectadas com a prática social. Para tanto, é preciso compreender que o conteúdo deve ser o mesmo, porém a forma de repassar o conteúdo, 
a didática, deve ser diferenciada no encaminhar das atividades, de acordo com o nível de aprendizagem, visando uma prática social transformadora.

Nesse sentido, reafirmamos a importância da escola do campo nas suas mais diferentes formas de organização, especialmente multisseriada. Saviani (2011) define a escola como uma instituição cujo papel consiste na socialização do saber elaborado, e não do saber espontâneo, do saber sistematizado e não do saber fragmentado, da cultura erudita e não da cultura popular. Assim, é dever do poder público garantir o acesso à educação escolar a todos, disponibilizando recursos e instrumentos necessários para o trabalho pedagógico/educativo, proporcionando, assim, pleno desenvolvimento no ser humano.

Contudo, cabe ressaltar que para construir e propor políticas públicas adequadas aos povos do campo é fundamental conhecê-la, direção na qual esta pesquisa foi realizada e buscou contribuir, apresentando elementos para um repensar da realidade e das condições de trabalho presentes nas escolas rurais, em particular aquelas pesquisadas, isto é, citadas neste estudo. Essas escolas possuem um papel de pertencimento dos sujeitos que ali vivem, a sua identidade, haja vista que há o interesse que os alunos estudem em escolas nas próprias comunidades e tenham perspectivas de futuro. Para isso, é necessário que a escola reconheça o seu papel social e proporcione meios para a oferta de uma educação que torne os sujeitos pessoas conhecedora, críticas, e acima de tudo, transformadores da realidade social.

\section{REFERÊNCIAS}

ARROYO, M. G.. Escola: terra de direito. Prefácio. In: ROCHA, M. I.A.; HAGE, S.M.(Org.). Escola de direito: reinventando a escola multisseriada. Belo Horizonte: Autêntica Editora, 2010.

BRASIL. Censo Demográfico 2017. Instituto Brasileiro de Geografia e Estatística. Panorama cidades. Disponível em:

https://cidades.ibge.gov.br/brasil/mg/indaiabira/panorama. Acesso em: 21 ago. 2019. 
BRASIL. Projeto Político Pedagógico das Escolas do Campo do Município de Indaiabira- MG, 2019.

DAVID, Z.G. Indaiabira, liberdade e evolução. Montes Claros- MG, 2000.

FERRI, C.. Classes multisseriadas: que espaço escolar é esse? 1994.

Dissertação (Mestrado em Educação) - Universidade Federal de Santa Catarina, Santa Catarina, 1994.

HAGE, S.M. Educação do campo na Amazônia: retratos de realidade das escolas multisseriadas no Pará (Org.). 1. ed. Belém: Gráfica eEditora Gutemberg Ltda, 2005.

LUDKE, M.; ANDRÉ, M. E. D. A. Pesquisa em Educação: abordagens qualitativas. São Paulo: EPU, 1986.

NUNES, K.de C.S. Escolas multisseriadas e os ideários pedagógicos: um estudo sobre as escolas do e no campo na região do Bico do Papagaio. 2018. Tese (Doutorado em Educação) - Universidade Federal de São CarlosSão Paulo, 2018.

PARENTE, C.da M.D. Escolas Multisseriadas: a experiência internacional e reflexões para o caso brasileiro. Ensaio: Avaliação e Políticas Públicas em Educação, v. 22, n. 82, jan/mar, 2014, p. 57-88. Fundação Cesgranrio. Rio de Janeiro, Brasil. Disponível em:

<http://www.redalyc.org/articulo.oa? id=399534053004>. Acesso em: 24 jan. 2020.

SAVIANI, D. Pedagogia histórico-crítica: primeiras aproximações. 11. ed. Campinas: Autores Associados, 2011.

VEIGA, I.P.A. A prática pedagógica do professor de Didática. Campinas, SP: Papirus, 1989.

Recebido em: 18 de outubro de 2021. Aprovado em: 30 de novembro de 2021. Publicado em: 09 de dezembro de 2021. 